\title{
Technological Vessels Online Monitoring Systems
}

\author{
Makrushin R. \\ RTK Digital Technologies, LLC
}

\begin{abstract}
This article is dedicated to the investigation of the possibility of the monitoring process physical parameters occurring in process vessels containing so-called dead zones. Modern production requires a qualitative, uniform throughout the volume of capacity, the technological process. During the working cycle of the processes flow in process vessels there are parts, the dynamics of processes in which differs from the dynamics of processes in other, more active parts of process vessel. Such activity is due to the circular liquids movement. Processes, chemical reactions in different turbulence areas proceed with a difference, and the results of measurements can vary significantly. The chemical reactions require control. An important issue is the possibility of equalizing process parameters in all parts of the vessel, including in dead zones. The author of the article proposes an monitoring technique of a process vessel entire working volume by means of a special measuring module in the form of a sleeve with a built-in measuring instrument. Two versions of this device are considered: stationary and mobile. It is pointed out the importance of selecting the shape of the device in order to avoid mechanical resistance during the process fluid movement. The principle of operation is proposed for both implementations of the device - comparison of the reference signals of the resonant sensor with the signal obtained from the trial measurement. The article is recommended for engineers involved in controlling of technological processes physical parameters in modern automated production.
\end{abstract}

Modern automated productions require continuous monitoring of all the processes main technological parameters and especially a precise connection between sensors and control systems, including both the central processing systems and the control computers. 


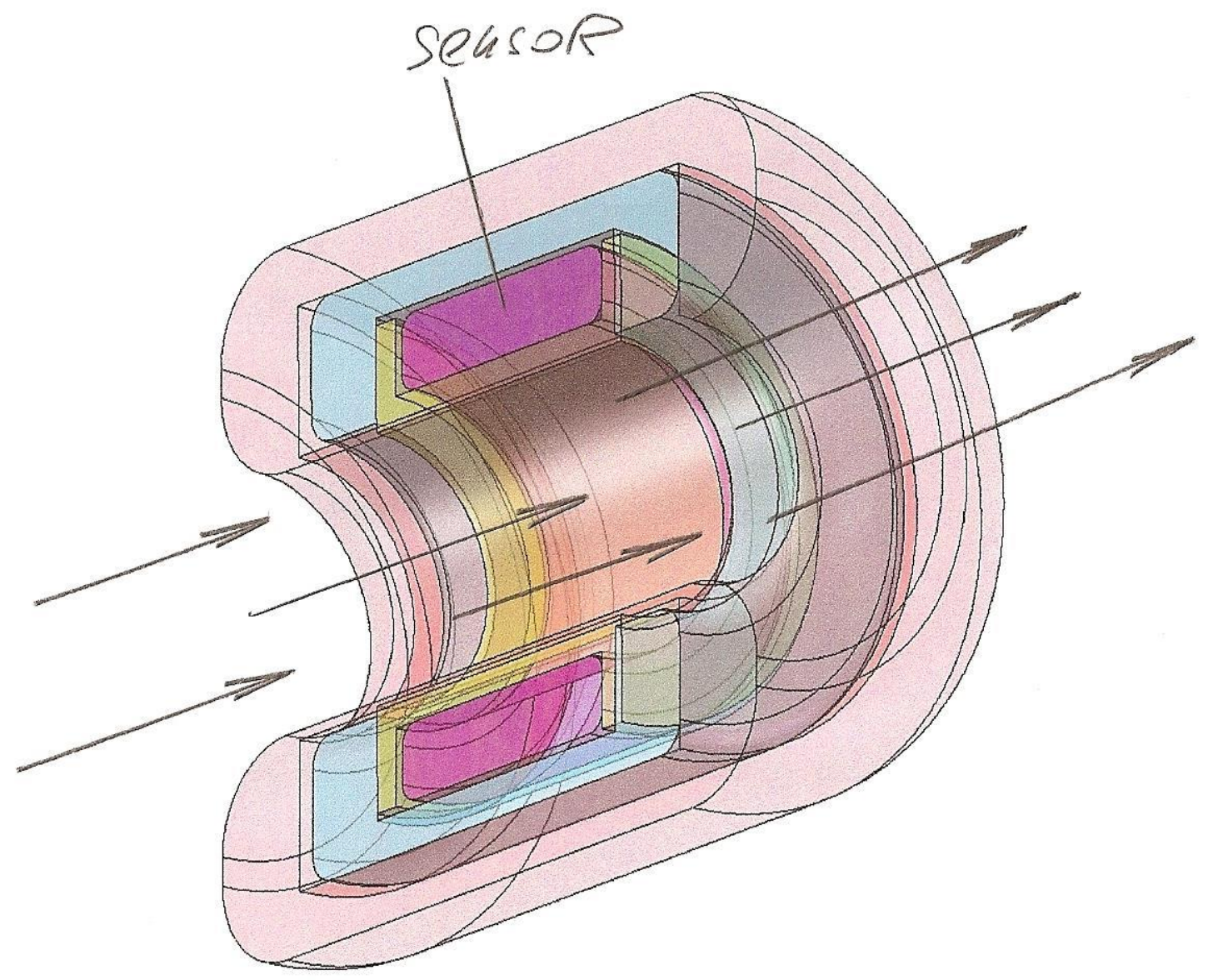

If, as an example, the modern pharmaceutical production is considered, then it is possible to find so-called dead zones in each process vessel of such production. Processes are slowed down in these dead zones and their dynamics radically differ from the same processes in active parts of the process vessel, where, as a rule, developed turbulent motion of process fluids.

In the corners of such vessels, the dynamic activity drops sharply and the results of chemical reactions can differ significantly from such results in the high turbulence zones. 


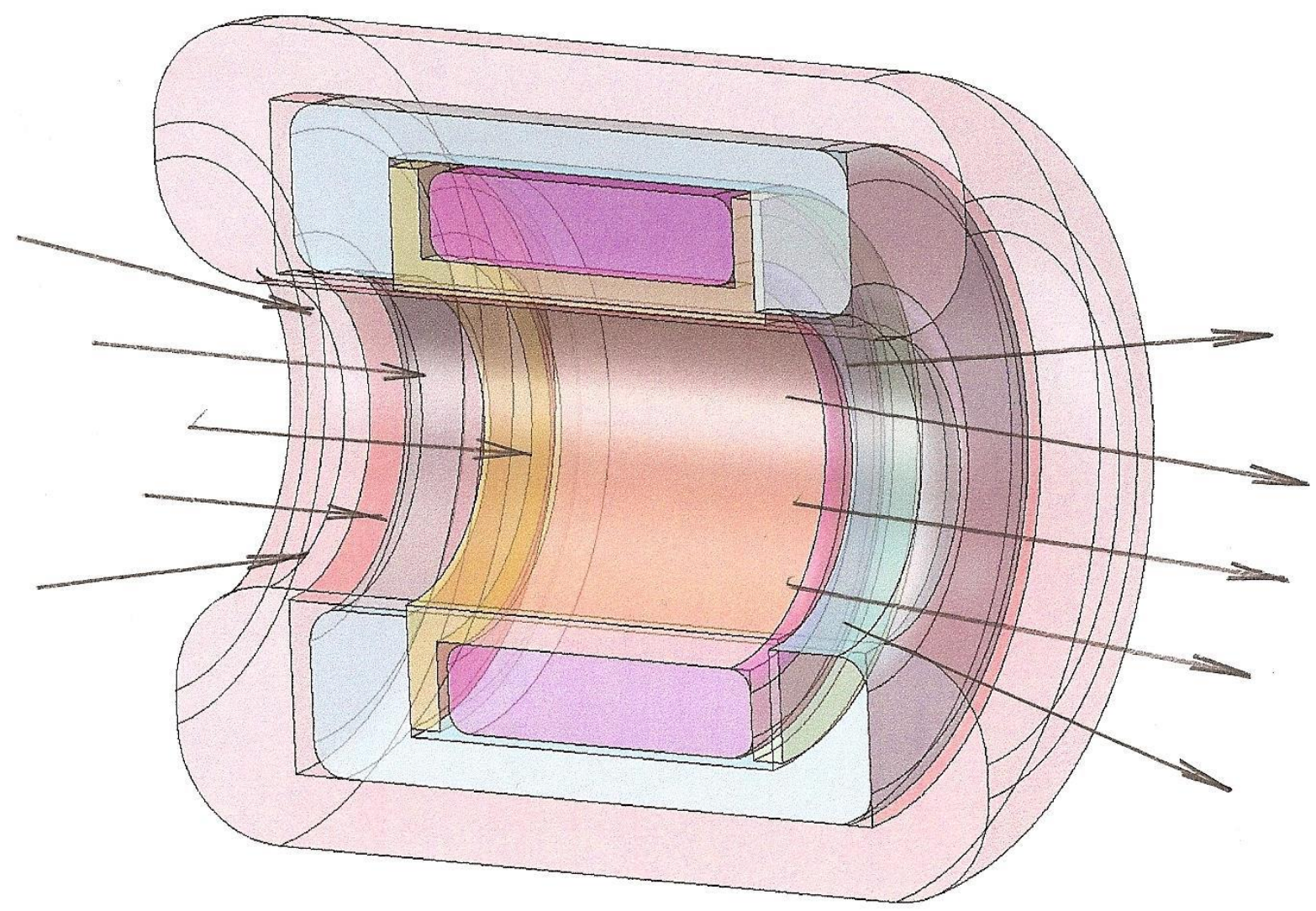

In order to control the chemical reaction activity of the entire working volume of the technological vessels and, as needed, equalize all the main operating parameters of the process and besides of that in order to ensure the same time of high-quality technological process at all points of the working volume of the technological vessel, on the basis of modern achievements and possibilities of non-contact sensor technology a sensor module is formed in the form of a sleeve. In that sensor module a sensor-solenoid of a certain design is built.

First of all, the sensor module is shaped in such a way that it completely corresponds to the basic properties of liquids that participate in the technological process initiated in the process vessel. 
The sensor module is designed in the form of a sleeve in which the ends are shaped in such a way that their edges are rounded. In combination with the cylindrical part of the sleeve it forms torus-shaped bushings into the cylindrical part of the sleeve.

Radii of toroidal surfaces depend on the viscosity of the controlled fluids. They are designed in such a way that would not cause a hydraulic resistance and do not slow down the movement of liquids through the inner bore of the sleeve.

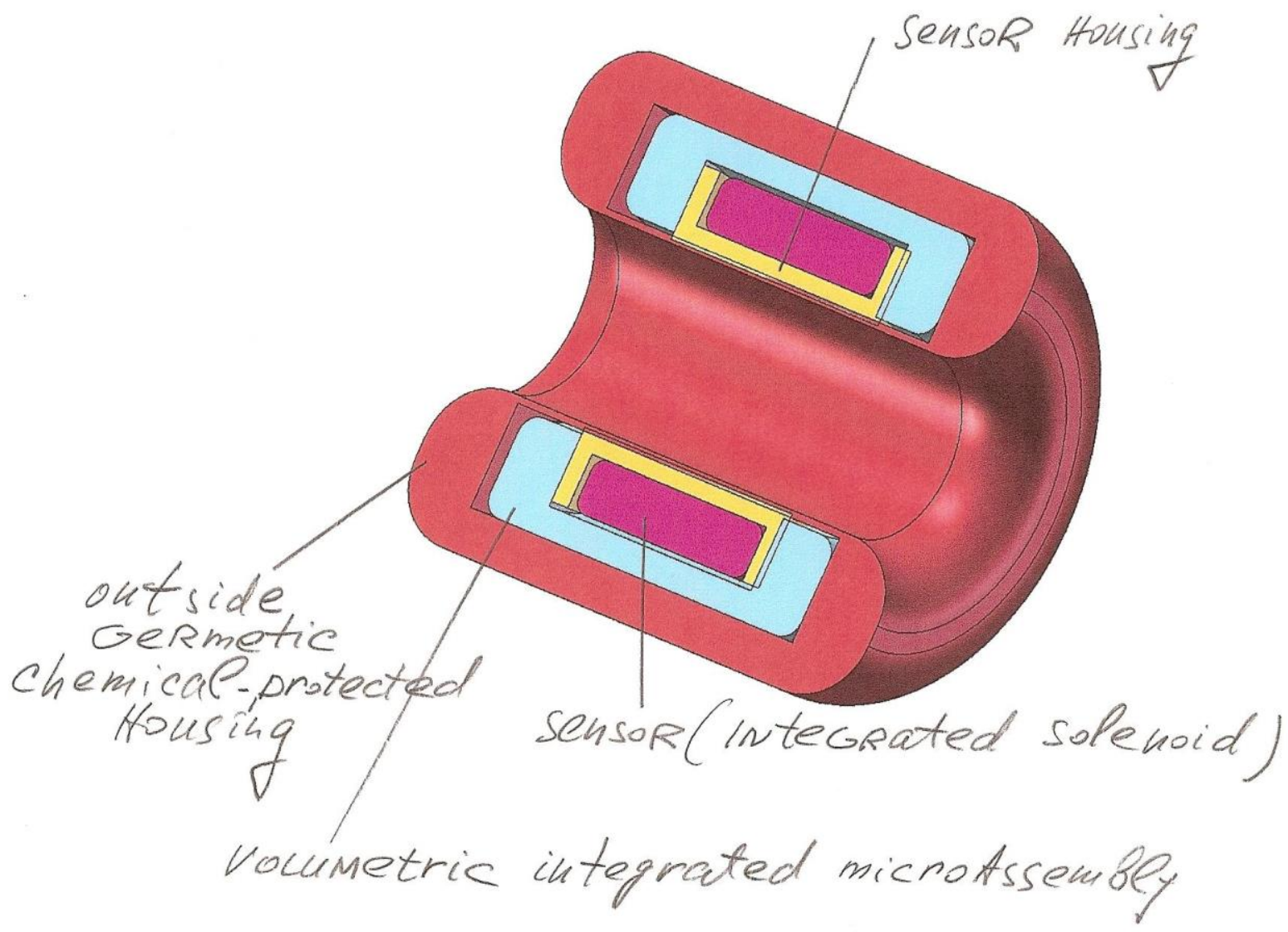

The height of microroughnesses on all internal surfaces of the sleeve is minimal, in order, to reduce the mechanical resistance to the movement of controlled liquids through the sleeve of the sensor module.

Thus, the sensor module is adapted to the specific conditions in the process vessel. 
Now, to deploy automatic control of necessary parameters in all phases of the process, appropriate mathematical models of both process fragments and the reactions of all system elements to the impedance-resonant background around the sensor module are needed.

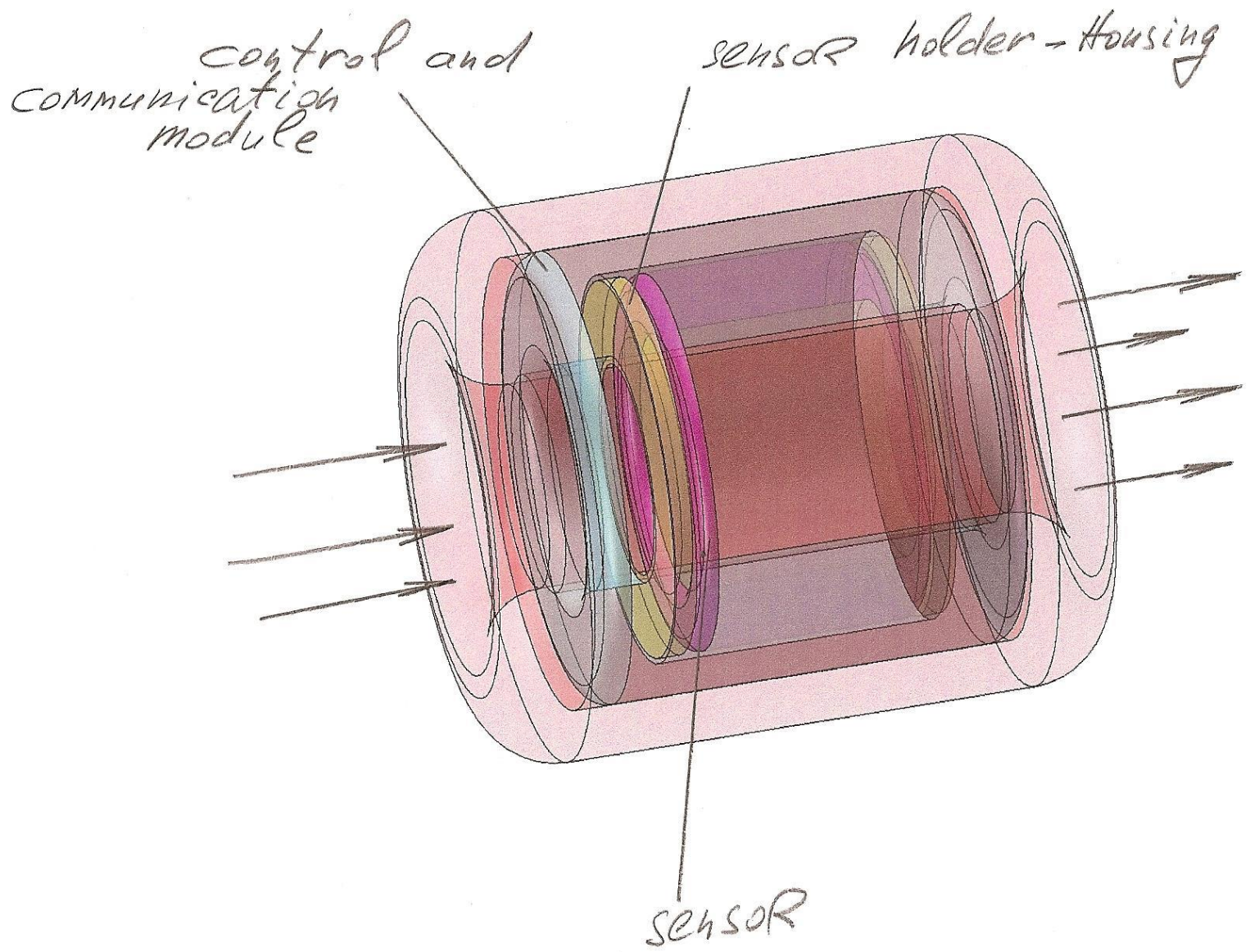

The sensor module has two basic implementations. The first one is for installation directly on the process pipeline before entering into the working volume of the process vessel within the production premises. The second is portable, intended for selection from the dead zones of process vessels of a sample of a technological solution or a mixture of technological solutions in a section of the pipeline on which the sensor module is mounted.

Both product implementations of the sensor module with all necessary internal and external infrastructure are laconic, made of plastic, usually PVC, compact and easy to use.

The principle of operation for both versions of the device is based on comparing the reference signals of the resonant sensor with the signal obtained from the trial measurement; 
The reference signal is obtained on fully compliant standards with a technological multicomponent or aqueous solution.

The sensor of the sensor module in combination with additional equipment of sensor devices fixes the slightest deviations from the reference signal. The sensitivity threshold is:

- for metals 0.000000005 grams;

- for radioactive isotopes, - 0.000000000001 grams;

- for silicates, - 0.000001 grams;

-for organic acids and compounds,- 0.0000001 grams;

All specified concentrations are indicated per liter of water.

The device in its simplest version does not separate or fix selectively every component of contaminants or impurities, but due to its sensitivity, it determines the $50 \%$ threshold of the concentrations of components and ingredients dangerous for the accuracy of the technological process or for the purity and stability of the technological process, contamination in drinking or process water.

Such high accuracy of the autonomous production device allows to constantly monitor the quality of the process, water used for technological purposes and even before reaching the concentration of impurities or impurities of a dangerous level, take measures to effectively eliminate them.

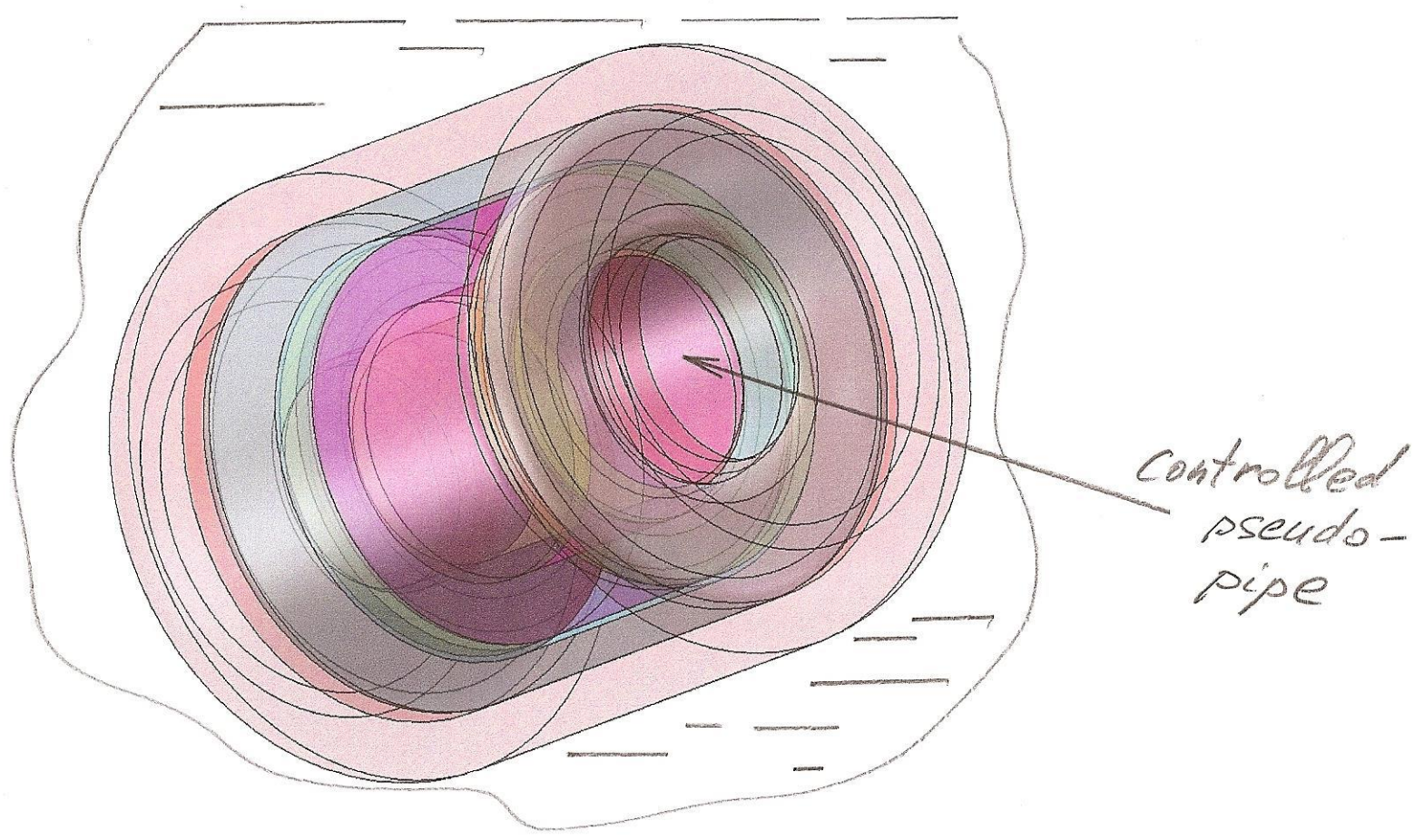


In the system of the sensor module, all electronic boards and micromodules should have the highest possible speed without additional energy resources.

Health standards and technological standards of most developed countries recommend the quality continuous monitoring of components and materials used in technological processes, as well as water and aqueous solutions, and the implementation of this requirement often encounters the absence of a reliable, easy-to-use and accurate instrument on the market whose price will allow it wide use.

The proposed implementations of the device in accordance with the author's proposals, fully comply with the standards requirements, both on the materials safety used, and on the application effect.

Both implementations of the device are technologically in production, do not require any special technologies for manufacturing applications and can be manufactured practically in small enterprises conditions at the optimal price.

\section{References}

1. Makrushin R.D. Kompleksnye sistemy aktivnogoonlain kontrolia v rezhime real'nogo vremeni i tekhnologicheskie osobennosti ikh proizvodstva [Complex systems of active online monitoring in real time and technological features of their production] / R.D. Makrushin //Molodoi uchenyi. - 2017. - № 48 (182). - C. 32-37.

2. Birk U., Livshits D. Vivo determination of acidity levels //20130178721.2013.JUSTIA Patents. URL: https://patents.justia.com/patent/20130178721 (application: 11.07.2018).

3. Birk U., Livshits D. In vivo determination of acidity levels// 8694091.2014.JUSTIA Patents. URL: https://patents.justia.com/patent/8694091 (application: 11.07.2018).

4. Birk U., Livshits D., Rabinovich R. Determination of attributes of liquid substances //9316605.2016.JUSTIA Patents. URL: https://patents.justia.com/patent/9316605 (application: 11.07.2018).

5. Birk U., Livshits D., Rabinovich R. Determination ofattributes of liquid substances //20130173180.2013.JUSTIA Patents. URL: https://patents.justia.com/patent/20130173180 
(application: 11.07.2018).

6. Flider G., Livschits G. Apparatus and method for fluid monitoring // 20120029845.2012.JUSTIA Patents. URL:https://patents.justia.com/patent/20120029845 (application: 11.07.2018).

\section{Translation of reference to original language}

Макрушин Р.Д. Комплексные системы активногоонлайн контроля в режиме реального времени и технологические особенности их производства / Р.Д. Макрушин //Молодой ученый. - 2017. - № 48 (182). - С. 32-37. 